\title{
Os Gestores na organização do CAPITALISMO BRASILEIRO (1930-1945)
}

\author{
Joäo Alberto da Costa Pinto* \\ joaoacpinto@yahoo.com.br
}

\begin{abstract}
Resumo: O artigo apresenta uma reflexão historiográfica sobre a ação dos Gestores na organização ideológica das bases nacionais do capitalismo brasileiro no período 1930-1945.
\end{abstract}

PaLAVRAS-CHAVE: Intelectuais, gestores, Góis Monteiro, Azevedo Amaral, capitalismo brasileiro.

O Estado capitalista brasileiro, redefinido no processo da Revolução de 1930, não nasceu intrinsecamente estruturado como espelho de demandas políticas claras da burguesia brasileira. Obviamente se afirmou dentro das contradições geradas no antigo modelo agrário-exportador, porque as bases do agrarismo monocultor, anteriores à Revolução de 1930, foram suficientes para produzir uma acumulação capitalista que, nas suas bases privadas, deu margem a práticas regionais de apropriação estatal de parte da mais-valia subtraída desse agrarismo monocultor, de modo a garantir um mínimo de organização e defesa do investimento. Antes de a burguesia se organizar nacionalmente como classe, já o Exército, por exemplo, era uma organização nacional. ${ }^{1}$ Desse fato resultaram, no Brasil, aspectos que tradicionalmente não se associam às formações sociais capitalistas clássicas.

A inexistência de uma burguesia nacional organizada como ator político, em interação com e dentro do Estado, produziu como uma de suas conseqüências o desinteresse dos capitalistas brasileiros por três dos pilares mais importantes para a constituiçăo e reprodução de uma

- Professor no Programa de Pós-Graduação em História da Universidade Federal de Goiás. Doutor em História Contemporânea pela Universidade Federal Fluminense. 
sociedade liberal, a saber, a organização militar, o sistema educacional e a burocracia pública. Particularmente o Exército. [...] Bem antes que as modernas associações de negócios começassem a tentar influir sobre o meio social brasileiro já o Exército havia nascido como organização. (SANTOS, 1978, p. 114)

Vista numa perspectiva geral, a assertiva acima de Wanderley Guilherme dos Santos é acertada e, a partir dessa constatação, são possíveis mais algumas indagações sobre a relação Classe e Estado no Brasil, o que fundamenta o sentido deste artigo. $\mathrm{O}$ que quero deixar previamente afirmado é que a organização nacional do Estado brasileiro nas décadas de 1920 e 1930 deu-se sem a presença hegemônica de uma classe nacional. O Estado até então era palco de "burguesias agrárias" regionais e somente o modelo militar autoritário é que haveria de consagrar as dimensões nacionais do capitalismo brasileiro, processo definido apenas com o Estado Novo de 1937 a 1945. De 1930 a 1937, os principais conflitos políticos nacionais deviam-se em grande parte às divergências de frações civis e militares dos gestores como classe dominante e à intervenção militar contra burguesias regionais, caso de São Paulo em 1932.

Nesse contexto, os gestores definiram-se como classe porque, através do aparelho de Estado, puderam ter acesso a partes significativas da mais-valia subtraída da exploração produtiva do complexo agrarista monocultor e da indústria em ritmo de expansão produtiva. Definem-se então esses gestores como uma classe dominante assalariada, não como valor de força de trabalho determinado pela concorrência produtiva e pela concorrência de mercado, mas pela lógica de critérios auto-referentes que reproduzem as distinções entre o valor da força de trabalho manual e da força de trabalho intelectual. Os indivíduos egressos de formas societárias não diretamente vinculadas à produção - as chamadas classes médias - são os quadros de classe dos gestores, como militares de carreira e/ou funcionários públicos civis. As práticas de organização no "interior" dos órgãos públicos do Estado, é que darão unidade de classe a sua atuação, apesar da multiplicidade de funções executadas dentro desse "espaço". Assim, os gestores, enquanto expressão societal concreta de uma classe, podem ser civis e militares, e a reprodução ideológica dessa classe em constituição histórica na década de 1930 só poderia ser elaborada com o discurso e as práticas do "autoritarismo instrumental". ${ }^{2}$ A trajetória e a obra de Azevedo Amaral são exemplares como expressão ideológica dos gestores. Intelectuais, como Azevedo Amaral, que elaboraram estudos 
teórico-historiográficos como modelos explicativos daquela realidade histórica, foram ideólogos de classe, não da burguesia (como é comum afirmar), mas expressão máxima da Intelligentsia nacional em formação na década de 1930, Intelligentsia essa que se definia como expressão político-intelectual de classe, como a expressão do máximo de consciência possível da única classe dominante nacional de práticas institucionais então constituída: os Gestores.

É da proposta do marxismo de João Bernardo que retiro o sentido interpretativo para a resolução dos problemas historiográficos referentes aos significados da relação Estado e classes sociais no capitalismo. O seu conceito chave de gestores será usado para escapar das armadilhas que a definição de um termo como classes médias proporciona ou deixa de proporcionar como elemento de análise. As práticas dos gestores unificam e sistematizam a ação conjunta das unidades privadas de produção (empresas) com a elaboração das condições gerais de produção (por parte do Estado), ou seja, os gestores afirmam-se nas suas práticas como a classe social responsável pela organização interinstitucional e intra-institucional das macroestruturas do capitalismo na sua relação básica: empresa Estado; organizam, portanto, os fundamentos da exploração da força de trabalho assalariada.

Classes sociais E estado no CAPITAlismo: os gestores COMO Classe dominante - UMA NOTA TEÓRICA

Os gestores são funcionários assalariados, embora não se possa falar da exploração direta de sua força de trabalho nas práticas produtivas realizadoras da mais-valia. Na verdade são eles que dirigem essa exploração e, a partir de cada unidade produtiva, formulam e organizam as capacitaçôes tecnológicas, consolidando assim a logicidade do sistema capitalista e consagrando a reprodutibilidade da empresa no conjunto das demais unidades produtivas. Por outro lado, são também os funcionários que, a partir do Estado, criam as condiçôes objetivas de infraestrutura que favorecem a sistematização das práticas capitalistas na saúde pública, educação obrigatória, serviço militar etc. Acrescente-se ainda o fato fundamental de que são também eles os responsáveis pela organização ampliada das estruturas de produção particular no mercado. Se os gestores das unidades privadas de produção organizam a produção para a sobrevivência na interconcorrência (agregada à produção específica de mercadorias em que estão envolvidos), os gestores do Estado organizam

João Alberto da Costa Pinto: Os Gestores na organização do capitalismo... 
as condições gerais de produção para que tais práticas interconcorrentes possam se realizar.

A seguir apresento alguns dos principais aspectos que norteiam a obra de João Bernardo (1977, 1979, 1987, 1991 e 2003), destacando os termos conceituais centrais para este artigo: os gestores como classe dominante no capitalismo e a questão do Estado Restrito e do Estado Amplo como elementos estruturantes dos ciclos de mais-valia na experiência histórica do capitalismo. Busco ainda testar essas possibilidades por meio de uma análise historiográfica do capitalismo brasileiro no seu momento de definição institucional nacional, isto é, discutir a experiência das práticas organizatórias do capitalismo brasileiro no período de 1930 a 1945, ápice das práticas de um modelo nacionalista de gestão "dirigida" pelo Estado Nacional. Essa análise revela que a especificidade nacional não implicava um isolamento econômico de fato, muito ao contrário, no ápice da organização nacionalista do capitalismo, o modelo em gestação tinha no Estado e na ação condutora dos gestores a realização de práticas integracionistas com o capital internacional. Assim, é necessário enfatizar que os fundamentos do nacionalismo, se vistos como expressão da autoridade do Estado, não são contraditórios com a internacionalização do capital; ao contrário, como afirma João Bernardo, quanto mais ativo é o Estado nacional na economia mais ele se substantiva como importador de capital, logo, como uma instituição capitalista nacional plenamente inserida no mercado global (BERNARDO, 1987). Essa assertiva pode ser comprovada pelos fatos observados no nacionalismo econômico do Estado Novo e pelas suas atividades como importador de capital dos EUA durante a Segunda Guerra Mundial, fatos em que a trajetória do General Góis Monteiro foi de suma importância.

Embora a presença dos gestores como classe dominante seja um elemento estrutural do modo de produção capitalista, é no campo da teoria marxista ortodoxa que essa assertiva é mais combatida, insistindose na tese das duas classes fundamentais - burguesia e proletariado -, sumariando-se as demais categorias sociais com o vaporoso conceito de "classes médias", e definindo-se o Estado capitalista como instituição guardiã dos interesses de classe da burguesia e seus quadros burocráticos como funcionários subalternos da burguesia (classe dominante). Ora, historicamente o Estado capitalista tem quase sempre se manifestado de modo organizado contra os interesses privados da burguesia. A incapacidade de a burguesia deixar de "pensar" e agir conforme seus interesses particulares (nos seus investimentos específicos), ou seja, sua incapacidade 
de pensar o capitalismo como sistema, leva desde o alvorecer do capitalismo a uma ação normativa do Estado contra os interesses privados da burguesia. Contudo, cabe lembrar que o Estado não é uma instituição em si, mas sim o resultado das relações inter-capitalistas. É o Estado que garante a relação fundante das condições gerais de produção para as empresas privadas. No Brasil, práticas capitalistas como expressões societárias de integração de um mercado nacional só começam a se estruturar na década de 1930, mais especificamente com o Estado Novo (1937-1945), quando as demandas locais da burguesia brasileira são subordinadas a uma lógica que lhe transcende o significado particular de classe. Assim, a revolução capitalista brasileira inaugurada com Vargas não poderia ser considerada como uma "revolução burguesa", pois nunca houve uma revolução com essas características no Brasil, mas uma revolução capitalista de gestores, o que é muito diferente em termos de enquadramento conceitual.

Os gestores não são possuidores de meios de produção no sentido clássico do significado de "posse" (ser o dono) no capitalismo, ainda que em momentos de complexa evolução produtiva esses meios de produção possam estar sob seu controle, o que atualmente é aceito quase que consensualmente, mesmo entre teóricos do pensamento econômico conservador. Pioneiro da tese de um "capitalismo coletivo" em formação histórica global é o trabalho publicado nos EUA, em 1932, por Berle \& Means (1988). ${ }^{3}$ A burguesia organizou historicamente as relações de dominação dos meios de produção, mas em práticas restritas fisicamente àquela posse de origem, ou seja, a burguesia organiza a produção e as relações sociais de exploração no âmbito específico da unidade de produção privada da qual é a proprietária. Contudo, entenda-se que o processo concorrencial entre empresas na conquista do mercado de consumidores não se efetiva apenas nesse "jogo" externo; ao contrário, o jogo de mercado - daí a tendência monopolista de todos os mercados capitalistas - já está previamente ganho por aquelas empresas que melhor articularam sua capacidade tecnológica na produção, melhor se preparando para a concorrência. Esse é o fundamento do "avanço" das unidades empresariais na concorrência intercapitalista. Entretanto, há aqui um ponto central: essas unidades produtivas não entram em competição pelo desejo solipsista de seus proprietários. Para essas empresas é necessário a existência prévia das condições gerais de produção (infra-estrutura sanitária, escolas, hospitais, estradas, polícia), isto é, tudo aquilo que organiza e possibilita a existência, em demanda aberta, de uma mão-de-obra para o trabalho nessas empresas 
particulares. Só com esses elementos é que se consagram historicamente as bases para a exploração da força de trabalho do proletariado. Capitalismo é isso: uma relação social sustentada nas práticas da exploração, ou seja, uma relação social de exploração do tempo dos trabalhadores. Não são as máquinas, nem as paredes de uma fábrica que definem as práticas do capitalismo. Ora, as empresas que conseguem "organizar" melhor essas práticas de exploração é que se sagrarão vencedoras na disputa "externa" do consumo de suas mercadorias, por uma razão simples, porque quanto mais se intensifica tempo de exploração, mais se torna "barato" o custo da produção das mercadorias.

Com o propósito de esclarecer a operacionalidade do conceito de Gestores, apresento a seguir uma definição geral, com exemplos da configuração capitalista internacional, ressalvando que, na experiência histórica brasileira, a estruturação das práticas capitalistas teve especificidades nem sempre assemelhadas ao modelo clássico de desenvolvimento capitalista, de onde João Bernardo retira os exemplos que ilustram sua argumentação conceitual, tanto na sua análise historiográfica como na análise teórico-política do capitalismo contemporâneo.

São necessárias algumas definições. A primeira delas, a definição de capitalismo que centraliza a argumentação de João Bernardo.

Capitalismo é o único sistema econômico que assenta na produção de mercadorias, ou seja, onde os bens são produzidos com a finalidade única da sua venda. [...] O capitalismo implica a criação, no processo de produção, do seu próprio mercado. Produz-se um número crescente de bens e só a venda no mercado permite que o capital entre em novo ciclo produtivo. Este regime implica uma concorrência permanente para o escoamento comercial dos produtos. [...] é a própria concorrência entre capitalistas particulares que leva à expansão do mercado em geral. $\mathrm{O}$ objectivo dos capitalistas particulares não é o de dividir entre si um mercado estático, mas, sobretudo o de expandir o mercado de que cada um dispõe. Para isso procuram permanentemente aumentar a produtividade. [...] a concorrência inter-capitalista no mercado assenta na concorrência inter-capitalista no próprio processo de produção; o mecanismo fundamental da concorrência reside na luta pelo aumento da produtividade a qual se processa inteiramente ao nível do fabrico dos produtos. O aumento da produtividade numa dada empresa pressupõe o conhecimento dos processos de fabrico nas restantes, [...] exigindo-se para isso uma relação tecnológica entre as unidades de produção. $\hat{\mathrm{E}}$ a partir de uma base comum de inter-relação tecnológica que as empresas 
vão entrar em concorrência pelo crescimento da produtividade. (Bernardo, 1979, p. 20-21)

Antes, porém, que esse processo econômico se realize integralmente é necessário que o Estado tenha desenvolvido, ou esteja a desenvolver, as chamadas Condições Gerais de Produção (CGP), condições, entre outras, como a "organização do sistema geral de ensino", "a extensão da medicina à generalidade da população", "medicina preventiva e a vacinação", "esgotos e novas condições urbanas" etc. (BERNARDo, 1979, p. 23-32). Em suma, condições gerais de produção que "ultrapassam os limites de cada empresa particular e constituem uma vasta teia, sem a qual essas empresas e o próprio capitalismo não poderiam existir" (BERNARDO, 1979, p. 36).

Com essa definição de capitalismo, cumpre notar agora como o autor conceitua as classes que o compõem enquanto modo de produção. Para João Bernardo são três as classes sociais no capitalismo. Classes não determinadas em si, como substâncias, mas, nas relações que estabelecem entre si. Além da classe explorada (o proletariado), o capitalismo apresenta mais duas classes formadas historicamente diante dos "dois aspectos fundamentais do pólo explorador do capitalismo":

a burguesia representando a parcelarização das empresas, a privatização da propriedade do capital; e uma outra classe, que consubstancia a integração tecnológica entre as unidades de produção, as condições gerais de produção; em virtude das funções predominantemente organizacionais que esta classe desempenha, na união entre os vários processos particulares de fabrico e, portanto, na orquestração do capitalismo como um todo, posso chamar-lhe classe dos gestores. (BERnardo, 1979, p. 36-37. Destaque do autor)

Ressalve-se que para o autor esse gestor não é um substituto do burguês, mas um contemporâneo seu. Destaque-se, na citação anterior, como o autor caracteriza o processo estrutural que dá existência histórica às classes dominantes no capitalismo. $\mathrm{O}$ comando pessoal da empresa privada em si é que define o burguês como proprietário; as relações de produção e de mercado, que impõem uma lógica de relações concorrenciais entre o conjunto sistêmico das unidades produtivas, são atividades que transcendem as práticas individuais desses proprietários (burgueses), sendo transferidas aos gestores, tanto na organização global do sistema econômico em que estão inseridas essas unidades produtivas, como na organização global do sistema político que organizará a estruturação do 
mercado, criando condições gerais de produção. Está aí definido o papel dos gestores do Estado. Mais um detalhe. A particularização do burguês a sua unidade produtiva não significa isolamento, significa, como diz João Bernardo, em outro momento da sua obra, "que cada unidade econômica veicula os aumentos de produtividade exclusivamente ao longo da linha de produção em que diretamente se insere" (BERnardo, 1991, p. 203), e que essa organização é que dará a caracterização de classe à burguesia. A unidade produtiva deve estar em relação com as outras unidades da mesma natureza, concorrendo no mercado e na produção por uma ampliação de sua capacidade produtiva. A burguesia se constituiu como classe pela organização particular de sua produção, premida pela concorrência com outras unidades produtivas. A classe dos gestores se constituiu pela organização integrada dessas unidades particulares, em paralelo à organização dentro do Estado das condições gerais de produção. Entretanto, afirma João Bernardo, apesar de se originar também da empresa privada, os gestores enquanto classe encontram no Estado o seu "campo privilegiado de existência", pelas funções de organização dos inter-relacionamentos globais exigidos pela sempre ampliada reprodução do capital.

Segundo João Bernardo, uma visão dicotômica dos conflitos sociais no capitalismo parece ultrapassada, se restringida à luta entre burguesia e proletariado. Para o autor, com o desenvolvimento do capitalismo, conferiu-se "uma importância prática cada vez maior à inter-relação das unidades de produção e às condições gerais de produção, condenando ao arcaísmo qualquer concepção centrada no isolamento das empresas" (Bernardo, 1979, p. 57). Dessa maneira, os gestores partilham com a burguesia o "controle dos aspectos decisivos do capitalismo"; ambas são, assim, "classes exploradoras e como tal se opõem ao proletariado" (1979, p. 59). A partir dessa constituição de práticas históricas, com a evolução do capitalismo, a integração tecnológica entre as empresas tende a progredir e, com isso, a função sócio-histórica da burguesia enquanto classe tende a se reduzir em detrimento da ampliação do controle do capital por parte dos gestores. Daí se poder dizer que se desenvolve dentro das estruturas do Estado, dependendo de cada situação, uma subalternização da burguesia como classe, diante dos gestores como classe progressivamente mais organizada.

Muitos outros elementos justificam historicamente considerar os gestores como classe, mas, para efeito de síntese, limito-me a mais uma rápida definição seguindo o argumento do autor. 
A classe gestorial, porque se relaciona com a integração das unidades econômicas no processo global e com a coordenação dessas articulações, desenvolveu formas integradas de propriedade do capital, que não é particularizada individualmente, mas unificada por grupos mais ou menos numerosos de gestores que, assim, detêm enquanto coletivo empresas, conjuntos de empresas ou até a totalidade da economia num país. (BERNARDO, 1991, p. 205)

Em suma, quanto mais se desenvolve a economia capitalista mais se consolidam os gestores como classe, considerados como a classe capitalista que, contemporânea da gênese deste modo de produção, expandese e reforça-se com o crescimento econômico, confundindo-se com ele o seu eixo de evolução" (1991, p. 216). No processo de expansão capitalista verifica-se crescentemente a "eliminação física" dos burgueses provocada pela falência do seu projeto empresarial na concorrência do mercado. Esses indivíduos assumirão funções de chefia em qualquer âmbito administrativo presente no capitalismo, tornando-se, portanto, gestores do capitalismo. Muitas vezes atuam como colaboradores nas empresas que já foram suas. Constata-se então, o fenômeno histórico do declínio progressivo da burguesia como classe dominante no capitalismo e da expansão progressiva dos gestores como classe dominante (BERNARDO, 1991, p. 216); a burguesia definha dando lugar a outra classe capitalista em expansão.

Quando a hegemonia de classe era da burguesia, o que se verifica com clareza até o fim da década de 1920, era comum que os gestores, no processo de sua ascensão como classe, estivessem dispersos "por campos e instituições várias", constituindo assim uma classe ainda incapaz de "comportamento unificado", razão por que eram confundidos "com os trabalhadores numa comum oposição à burguesia". Esse momento, de efetiva ambigüidade de classe, "permitiu que grandes movimentos da classe dos trabalhadores, inicialmente dirigidos para a destruição do modo de produção capitalista, acabassem afinal reconvertendo-o em formas novas, acelerando assim o seu desenvolvimento e consolidando-o" (BERNARDO, 1991, p. 217). Esse fenômeno, tão característico das lutas anticapitalistas no século XX, acabava por reforçar a apropriação da mais-valia relativa, isto é, por reforçar um capitalismo cada vez mais organizado, cada vez mais sistematizado pela classe dos gestores. O corolário desse fato, sob o ponto de vista dos trabalhadores, é paradoxal, porque significa que eles presenciaram concretamente, no seu próprio campo de lutas, a transformação de um ex-aliado em um inimigo de classe.

João Alberto da Costa Pinto: Os Gestores na organizaçāo do capitalismo... 
Nas 959 páginas do monumental estudo que desenvolveu sobre a história do fascismo no século XX - Labirintos do fascismo: na encruzilhada da ordem e da revolta (2003), João Bernardo apresenta inúmeras e detalhadas descrições historiográficas sobre a questão da relação gestores e capitalismo. Para efeitos de conclusão deste item, delas escolhi uma que apresento a seguir de modo integral.

Diz o autor que os gestores "surgem como o eixo de articulação de todas as variantes do capitalismo moderno" (BERNARDo, 2003, p. 307). São três as variantes do capitalismo moderno: a variante democrática do New Deal nos EUA - um modelo de capitalismo identificado como keynesiano; a variante soviética, como expressão de capitalismo de Estado; e por último a variante fascista européia. Será importante observar a análise que o autor dedica a cada um desses modelos, porque, a partir dela e daquilo que aqui apresento, terei elementos para pensar a relação dos gestores brasileiros na revolução capitalista brasileira.

Segundo Joâo Bernardo, no período entre as duas guerras mundiais, a burguesia "mostrou-se incapaz de se renovar e de remodelar o sistema econômico. Perante esta falência histórica da classe que até então havia sido hegemônica foram os gestores quem assumiu a direção dos acontecimentos, salvando o capitalismo" (2003, p. 306). "Salvação essa demarcada nas três variantes referidas acima e caracterizadas sumariamente a seguir.

No modelo do keynesianismo do New Deal, "conservaram-se as instituições burguesas", mas já remodeladas pelos gestores, com o imperativo político definindo-se pela manutenção da ordem. No pós-1929, pela própria natureza da crise macroestrutural, os trabalhadores, apesar de suas lutas, foram crescentemente alijados dos centros decisórios - por exemplo, não se constituiu nos EUA a partir desse momento um forte Partido Comunista de bases nacionais. $\mathrm{O}$ autor define a ação dos gestores dentro das instituições burguesas, com os trabalhadores crescentemente marginalizados nas mesmas, como uma "modalidade de manutenção da ordem" (Bernardo, 2003, p. 306).

O inverso aconteceu na União Soviética. Conforme o autor, "enquanto o proletariado procurava a aliança dos gestores para destruir ou transformar as relações sociais de produção, confundindo assim a burguesia com a totalidade do capitalismo" (2003, p. 307), os gestores apropriavam-se do apoio do proletariado para apenas modificar o estatuto jurídico de propriedade, "de maneira a desenvolver formas de apropriação adequadas ao caráter coletivo da classe gestorial e a retirar à burguesia a exclusividade do controlo do capital. Nesta indefinição entre relações de 
propriedade e relações de produção" (2003, p. 307), afirmaram-se as "grandes derrotas do proletariado" e os "mais macabros paradoxos do socialismo" (p. 307). Segundo o esquema sugerido pelo autor, na experiência dos socialismos ortodoxos contemporâneos, dos quais a experiência do stalinismo soviético é o grande paradigma, a equação passa a ser: "gestores + proletariado/burguesia" (BERNARDO, 2003, p. 307).

A situação do fascismo obedeceria a um esquema híbrido. Como na ortodoxia stalinista, o fascismo também "institucionalizou a mobilização do proletariado sob o comando dos gestores"; no entanto, a "afinidade do fascismo com o New Deal e com o keynesianismo resultou da manutenção das instituições burguesas na sua aparência exterior, embora a burguesia ficasse relegada a um lugar secundário" (2003, p. 307). O fascismo impunha à burguesia a ameaça do proletariado para afirmar os gestores como condutores do capitalismo, ou seja, no fascismo, os gestores mantiveram o quadro capitalista de feições burguesas, respeitando-se o quadro da ordem, mas acrescentando-lhe o medo da "revolta, suscitado pelos ecos da mobilização proletária. Num esquema: gestores + burguesia + proletariado" (2003, p. 307).

Diante desse quadro descritivo e corroborando a argumentação do autor, posso levantar para o caso brasileiro a seguinte hipótese explicativa: no fascismo brasileiro (na política autoritária do Estado Novo de 1937 a 1945), a organização capitalista consolidou-se com o esmagamento dos movimentos sociais de bases populares-proletárias, principalmente do movimento aliancista (centrado institucionalmente no PCB e na Aliança Nacional Libertadora), impedindo-lhes a crescente manifestação autoorganizada. Por outro lado, por meio dessas práticas centralizadoras a burguesia agro-industrial foi gradativamente submetida ao domínio de práticas dirigistas estatais, práticas de evidente subordinação de classe. Em meio às práticas institucionais progressivamente centralistas do governo Vargas, já percebidas anteriormente ao golpe de 1937, uma classe organizou-se nacionalmente: os gestores. Nas Interventorias estaduais, nos Conselhos Técnicos, e nas demais agências de regulação, consolidaram-se os emblemas da racionalização da democracia corporativa autoritária, expressão cabal do fascismo brasileiro. Esse termo conceitual programático, amplamente divulgado no período em questão, originado da obra matricial do pensador romeno Mihail Manoilesco, teve em Azevedo Amaral o seu maior divulgador no Brasil. A partir dessa noção e de um significativo conjunto de estudos sobre o Brasil, Amaral obteve as ferramentas para elaborar historiograficamente um complexo modelo expli- 
cativo da realidade brasileira, ${ }^{5}$ que se firmou como um norte ideológico de classe. No entanto, muito antes dessas práticas institucionais, já uma instituição junto e dentro do aparelho de Estado realizava-se como a estrutura endógena fundamental da organização estatal capitalista: o Exército. Foi na prática gestora do Exército, como estrutura endógena do fascismo brasileiro, que se organizaram algumas das bases fundamentais do capitalismo brasileiro. E nesse sentido, a trajetória do General Góis Monteiro foi a que melhor expressou os fundamentos da visão de mundo dos gestores na efetivação da democracia corporativa autoritária, com as bases programáticas da "Doutrina Góis Monteiro" surgindo como a expressão máxima da Intelligentsia militar fascista do período, porque fundamentadas num ponto de integração das demandas corporativas militares com as demandas globais do capitalismo brasileiro. Isto é, segundo o modelo de Góis Monteiro, a organização do Exército aparecia como capaz de consolidar as condições gerais de produção do capitalismo brasileiro. Góis Monteiro e Azevedo Amaral são, portanto, a expressão máxima da consciência possivel dos gestores, revelando a visão de mundo da única classe dominante de feições e práticas institucionais nacionais. Com Azevedo Amaral, o Estado Novo encontrou as justificativas sociológicas e historiográficas para as demandas dos gestores como classe dominante; e com a Doutrina Góis, esses mesmos gestores encontraram os fundamentos da racionalidade administrativa-produtiva que haveria de se estabelecer no eixo fundamental da organização capitalista brasileira.

Para melhor elucidar o papel dos gestores no capitalismo brasileiro enfatizo, ainda que muito rapidamente, a questão dos Conselhos Técnicos para uma análise de suas práticas institucionais.

Afirma Diniz (1999, p. 28) que os Conselhos Técnicos viabilizaram um sistema decisório mais aberto às demandas econômicas privadas sem, no entanto, subverter a primazia da elite técnica, a primazia dos gestores. Nesse sentido, as práticas institucionais dos Conselhos Técnicos assemelhavam-se às práticas do modelo norte-americano no período do New Deal, principalmente após a organização do Conselho de Produção de Guerra (GALBRAITH, s.d., p. 37-42), quando o governo "negocia" com o setor produtivo privado - que sempre fora hostil à gestão rooseveltiana - o redirecionamento produtivo para a guerra, sem, contudo, abrir mão do controle e da logística dos gestores, os "New Dealers". No Brasil, os Conselhos já eram indagados como elemento estrutural por Oliveira Vianna em 1930. Nos termos de Oliveira Vianna (1974, p. 147), os Conselhos Técnicos haveriam de ser o instrumento para a organização das condições 
gerais de produção e, principalmente, para a organização da exploração da força de trabalho, tanto que a sua institucionalização foi articulada pelo Instituto de Organização Racional do Trabalho (IDORT), órgão criado por empresários de São Paulo em 1931. Com a consolidação dos Conselhos nas práticas gestoras do Estado, o IDORT continuou a ter um papel determinante junto ao governo federal, mesmo quando o seu presidente de honra - o oposicionista de Vargas, em 1937, e governador de São Paulo Armando de Salles Oliveira - foi expulso do país (SouzA, 2005, p. 219-231). Num relatório de 1944, apresentado a um desses Conselhos - o Conselho Nacional de Política Industrial e Comercial do governo federal - Roberto Simonsen diagnosticou o seguinte quadro:

Devido à nossa falta de aparelhamento econômico a às condições em que se apresentam os nossos recursos materiais, a renda nacional está praticamente estacionária, não existindo possibilidade, com a simples iniciativa privada, de fazê-la crescer, com rapidez, ao nível indispensável para assegurar um justo equilibrio econômico e social. (SIMONSEN, 1944, p. 14)

Ou seja, segundo o diagnóstico de Simonsen, de 1944, o fato elementar da necessária articulação das Condições Gerais de Produção com as empresas privadas, ainda não se concluíra como programa básico. Mas, note-se, os instrumentos para a presumida articulação necessária à superação dos problemas indicados já estavam apontados e não seria a burguesia que os acionaria, mas sim os gestores.

Outro fato a acrescentar é o de que as práticas institucionais nacionalistas dos gestores do Estado brasileiro não se opunham à participação do capital estrangeiro na atividade econômica brasileira, muito ao contrário. Azevedo Amaral no seu livro de 1938, Estado autoritário e realidade nacional, manifestava-se enfaticamente em favor da importância fundamental do capital estrangeiro para a economia do Brasil (apud DinIz \& Boschi, 1978, p. 63).

Desse modo, um argumento deve aqui ser enfatizado. No capitalismo, o Estado é "um princípio de organização geral das instituições" (BERNARDO, 2003, p. 26), porque nas práticas capitalistas a força de trabalho explorada, realizadora de mais-valia, não está socialmente afirmada apenas como sustentação econômica dos exploradores, mas recebe dessas práticas institucionais também o quadro e as formas gerais de sua própria organização.

Joāo Alberto da Costa Pinto: Os Gestores na organização do capitalismo... 
O Estado capitalista não é apenas uma plataforma que as classes dominantes usam para se constituírem internamente nem um simples instrumento de opressão dos explorados. [...] Princípio de autoorganização das classes capitalistas, o Estado é ao mesmo tempo o princípio da hetero-organização da classe trabalhadora. (BERNARDO, 2003, p. 26)

Em suma, é sempre "em função da produção e da expropriação da mais-valia que se devem definir as classes sociais no capitalismo" (BERNARDo, 2003, p. 26), e, desse modo, creio ter pouco sentido historiográfico perceber o Estado como "palco" de "atores", em que "frações" da burguesia lutam para afirmarem-se hegemonicamente. Ora, essa é uma percepção reificada da dialética das contradições sociopolíticas do capitalismo brasileiro porque, ao centrar-se a investigação nas frações que lutam pela hegemonia, quase sempre se escamoteia o fato principal, o de que todas essas práticas organizam em uníssono as bases estruturais das práticas da exploração da mais-valia e, mais importante, escamoteia-se a presença dos gestores como classe dominante capitalista. ${ }^{6}$

Antes de apresentar uma caracterização mais detalhada dos fundamentos ideológicos da ação prática de Góis Monteiro e de Azevedo Amaral, é necessária uma rápida justificativa teórico-historiográfica para esta questão chave: os intelectuais percebidos como Intelligentsia, como produtores de uma visão de mundo de classe.

O TRABALHO TEÓRICO dOS INTELECTUAis (INTELLIGENTSIA) NA FORMULAÇĀO E REALIZAÇẢO PRÁTICA DAS VISŐES DE MUNDO DE CLASSE

Em todas as práticas de configuração do capitalismo nacional, nos seus momentos iniciais de organização da acumulação, os gestores, além da organização produtiva, assumem também o papel de porta-vozes de uma espécie de "consciência pública" da Nação. Das suas práticas institucionais nascem formulações ideológicas que se constituem como mitologias de fundação. E é nesse aspecto específico, o da construção ideológica do sentido da nação, que os produtores de Historiografia, por exemplo, cumprem funções de ideólogos, fazendo com que a Historiografia em si afirme-se também como um campo aberto de lutas teóricas e políticas, campo aberto de lutas de classe, quando o trabalho historiográfico de autores de expressão nacional - Nelson Werneck Sodré, Oliveira Viana, Caio Prado Júnior, Roberto Simonsen, Gilberto Freyre, ${ }^{7}$ por exemplo -, torna-se, nas décadas de 1930 e 1940, a expressão do máximo de consciên- 
cia possível dessa classe dominante no capitalismo brasileiro. A expressão Intelligentsia é um recurso conceitual que sintetiza essas práticas, daí ser possivel definir os membros da Intelligentsia como ideólogos de classe, os quais, com sua ação, envolveram-se com a organização do processo de constituição do capitalismo brasileiro de modo não a levar unidade às práticas em si desse capitalismo em constituição (1930-1940), mas a conferir unidade ideológica aos indivíduos - os gestores, que, como classe social procuravam afirmar sua hegemonia política dentro desse processo histórico.

Parto do suposto de que a teoria só se torna expressão de visão de mundo, quando a prática política do intelectual produtor dessa teoria está mediada pelas práticas institucionalizadas de um determinado campo cultural. Esse campo cultural, como espaço mediador, concentra em si as determinações ideológicas da superestrutura como momento de expressão dos carecimentos estruturais impostos pela lógica do conflito de classes. As determinações ideológicas da superestrutura afirmam-se sempre como a expressão das práticas de complexos institucionais agregados diretamente à reprodutibilidade material da sociedade. Os agentes da reprodução material da sociedade são as classes sociais. Classe social é a expressão teórica da condição material a que os indivíduos estão determinados pela esfera produtiva, o mundo da exploração da força de trabalho e dos imperativos da lógica do valor de troca. Cada indivíduo, assim, vê-se contingenciado pelas determinações dessa esfera produtiva. Inclusive os intelectuais. Mas, ao contrário de um indivíduo vinculado diretamente à reprodução material da sociedade (um operário de qualquer setor industrial, por exemplo), o intelectual é um indivíduo diretamente vinculado à reprodução material da superestrutura; é um trabalhador, como o operário, mas não é membro da classe operária, isto porque carrega em si, na sua prática particular, uma autonomia relativa diante das determinações específicas impostas a cada classe social em face da imediata reprodutibilidade material da sociedade, determinações sempre marcadas pelo conflito de classes. Os intelectuais, pela natureza específica do uso social de sua força de trabalho, constituem-se, em princípio, numa camada intersticial diante das demandas de classe em conflito. Mas, como se constituem "organicamente" como a força de trabalho que realizará a reprodutibilidade material da superestrutura, essa autonomia parcial será determinada tão somente na esfera da criação ideológica, porque, como são a força de trabalho da superestrutura, logo são também uma fração ativa da classe dominante, responsável pela organização ma-

João Alberto da Costa Pinto: Os Gestores na organização do capitalismo... 
cro-estrutural do capitalismo - os gestores. Os intelectuais são então os agentes da afirmação ideológica hegemônica. Assim, esse caráter intersticial é apenas uma figuração formal descritiva, visto que todo intelectual que se reproduz como tal na lógica das instituições capitalistas, principalmente aquelas da organização das práticas ideológicas, é nesse sentido um Gestor.

É com a força de trabalho dos intelectuais (enquanto Intelligentsia) que se cimentam os vetores ideológicos da sociedade. Para tanto, essa força de trabalho impõe, como necessidade lógica da reprodução material da superestrutura social, a existência dos espaços institucionais de criação (a imagem da fábrica de ideologias salta logo aos olhos, embora seja uma imagem simplificadora), o que lembra, principalmente, as agências oriundas de composição estatal, aquelas agências de ciência e cultura, e aquelas originadas da sociedade civil, como jornais, revistas, partidos políticos etc.

Em termos gerais e para uma caracterização comum a todas as formações sociais capitalistas, os intelectuais, dentro desses espaços institucionais de reprodução material da superestrutura, vêem-se diante de confrontos de interesses demarcados como se fossem interesses próprios, individuais. Como é uma categoria social que não se pensa como classe, por quase sempre acreditar que define o seu trabalho como expressão de sua vontade individual dentro desses espaços institucionais (institutos de pesquisa, departamentos universitários etc.), constituemse e determinam-se campos de interesses, os quais, pelo solipsismo "natural" dos seus membros, logo se tornam o máximo de "mundo real" desses indivíduos intelectuais, ou seja, uma expressão de sociabilidade determinada pelas contingências, significados e valores de uso de cada indivíduo, no máximo que pode alcançar de hegemonia dentro desse mesmo campo de interesses. Em suma, os intelectuais enfrentam-se como indivíduos em luta pelo controle do campo cultural em que estão envolvidos.

No entanto, essa manifesta e explícita alienação, imanente à própria atividade social do intelectual em certos momentos, é abalada quando alguns desses indivíduos produzem uma "mercadoria" cujo valor de troca social transcende os limites específicos do conflito do campo cultural a que estão submetidos e se transforma também em uma mercadoria cujo valor de troca será a expressão ideológica dos valores de uso de uma determinada classe ou fração de classe no confronto social pela defesa dos seus interesses. Essa "mercadoria" é a visão de mundo. 
É da obra do pensador romeno-francês Lucien Goldmann que extraio a definição de "visão de mundo", termo hoje pouco usual na historiografia, mas de grande eficácia instrumental para os propósitos desta análise. Lucien Goldmann afirma que visão de mundo "é um ponto de vista coerente e unitário sobre o conjunto da realidade", apresentando, no entanto, uma ressalva: "o pensamento dos indivíduos - com pequenas exceções - é raramente coerente e unitário". Dessa maneira, para ele visão de mundo é "o sistema de pensamento que, em certas condiçôes, se impõe a um grupo de homens que se encontram em situações econômicas e sociais análogas, isto é, a certas classes sociais" (GoldmanN, 1979, p. 73). Esse conceito goldmanniano é sintetizado por Michael Löwy, da seguinte forma:

é a partir da classe social, da consciência possível de classe, que vai se desenvolver a visão de mundo de uma classe, e essa visão de mundo vai se manifestar em seu comportamento social. Isto é importante porque a visão de mundo não é só um fenômeno espiritual, é algo que se manifesta tanto na prática, no comportamento econômico, social, político, real da classe, quanto ao nível conceitual, através de obras culturais, literárias, artísticas e outras. (LOWY, 1986, p. 75)

Assim, quando utilizo neste artigo a expressão "visão de mundo", quero com isso afirmar que toda a produção intelectual da Intelligentsia brasileira aqui evidenciada foi entendida como expressão de consciência de classe. Melhor dizendo: a produção teórica de Azevedo Amaral e a de Góis Monteiro, entendida como expressão de classe, neste caso, é entendida como expressão de visão de mundo dos gestores e não da burguesia, que na década de 1930 é por mim entendida como uma classe dominante subordinada. Uma classe permeada por distintas vicissitudes estruturais regionais, uma classe ainda marcada na sua estrutura interna por fortes fracionamentos político-regionais: a fração burguesa industrialista de São Paulo e a fração burguesa agrarista de Pernambuco, por exemplo. Em 1930, os gestores eram a única classe dominante com características e proporções nacionais.

Enfim, a "mercadoria", inicialmente apresentada pelo intelectual que a produziu como valor de troca dentro do campo cultural institucional em que se circunscrevia sua sociabilidade (termo com o qual procura obter certa hegemonia entre seus pares), em certos momentos, ao se tornar visão de mundo e apresenta uma racionalidade intrínseca capaz de oferecer respostas ideológicas a determinado grupo, fração ou classe social, na

João Alberto da Costa Pinto: Os Gestores na organização do capitalismo... 
sua relação diante do conflito de interesses com outras classes, torna-se nesse momento a prática da força de trabalho desse indivíduo-intelectual. Essa prática, para o historiador, nunca deve ser apenas biografia, mas prática transindividual e, nos exemplos discutidos, práticas teóricoinstitucionais de Intelligentsia. Mas, nessa equação, falta discutir ainda uma questão: quando e como isso acontece? Isso acontece porque a racionalidade intrínseca desse modelo teórico produzido fundamenta-se por meio de "estruturas significativas" ${ }^{\text {q }}$ que, na lógica própria da ciência, acabarão por afirmar o "máximo de consciência possível"9 de um grupo, fração ou classe social, numa situação limite das suas lutas contra outros grupos, frações ou classes. Ou seja, esse processo ocorre quando a "mercadoria" inicialmente apresentada como ciência se faz socialmente ideologia, não como falsa consciência, mas como o máximo de consciência que os indivíduos poderiam ter tido no limite do conflito social, quando a ciência deixa de ser o valor de troca do intelectual e passa a ser o valor de uso - a ideologia - dos agentes de um grupo, fração ou classe social, valor de uso que proporá sempre as possibilidades das alternativas transformadoras nas lutas sociais. Tanto que na lógica do conflito de classes há modelos explicativos "vencedores" e "derrotados". Um modelo explicativo - uma teoria da História do Brasil, por exemplo - não é boa teoria ou má teoria, não é certa ou errada, apenas pelo seu caráter intrínseco, mas também porque é expressão direta da derrota ou da vitória no esteio da luta de classes sociais que imantam a totalidade histórica. $\hat{E}$ dessa maneira que vejo a produção e a trajetória da intelligentsia brasileira.

Poder-se-ia contemporizar essa análise com a idéia mannheimiana do grupo de intelectuais livres, mas, segundo minha análise, essa é uma impossibilidade estrutural. Não há intelectual nem grupos intelectuais de "afinidades" sem a determinação estrutural de sua posição de classe dentro da reprodutibilidade da mais-valia na sociedade capitalista. Uma das possibilidades de apreensão conceitual da realidade de classe dos intelectuais é oferecida pelo método de Lucien Goldmann, e essa apreensão só poderia ser concretamente alcançada pelo estudo das estruturas significativas da obra desse intelectual. Essas estruturas significativas, determinantes para a caracterização das práticas institucionais, é que fornecerão a substantividade da explicação do sentido do grupo-instituição; afinal toda prática é institucional, não existem práticas desvinculadas de instituições.

A explicação da realidade imediata em que está envolvido institucionalmente o intelectual acaba por caracterizar apenas a descrição da sua 
intervenção individual, ficando a investigação reduzida a uma descrição de eventos. Ao indagar o sentido estrutural da obra do intelectual - o que me obriga a ter de estudar e analisar o máximo do conjunto de sua obra -, é então possível encontrar os significados diferenciadores da posição manifestada, cabendo lembrar, contudo, que essa não é uma relação mecânica. Existem elementos de mediação que são obrigatórios e o mais importante é aquele que impõe a comparação das estruturas significativas.

Por outro lado, as circunstâncias sociais e institucionais da classe a que o autor se vincula não devem ser observadas como externas à obra. Em termos formais, é claro que essas circunstâncias têm uma lógica própria, mas num sentido historiográfico operacional essa lógica própria, em última instância, está determinada pela relação com a obra, relação que não significa expressão de homologia. A totalidade parcial, expressão do ato compreensivo da obra, define-se também como estrutura portadora de significado social, significados de classe e/ou de grupo, que dão as marcas ontológicas do autor e de suas relações societárias. Esse contexto que também incorpora a obra, e não apenas a ação do intelectual, é para Goldmann uma totalidade ampliada. A compreensão do ideário político e das afinidades ideológicas dessa totalidade ampliada possibilita a explicação da obra. Assim, é possível ver o significado sócio-político de uma obra como expressão de uma determinada visão de mundo, que é um fato social e não algo simplesmente subjetivo do autor.

A AÇÃO DOS GESTORES E SUA INTELLIGENTSIA NA ORGANIZAÇÃO DO CAPITALISMO BRASILEIRO: as PRÁtICAS IDEOLÓGICAS-INSTITUCIONAIS dE GóIS MONTEIRo e Azevedo AMARAL

Para dar mais amplitude a esse quadro geral de uma classe em formação no Brasil, nas décadas de 1930 e 1940, apresento agora, de modo sucinto, alguns aspectos relacionados ao general Góis Monteiro, o gestor militar que procurou enquadrar o processo da revolução capitalista brasileira nas diretrizes gerais do intervencionismo estatal. Essa atuação o coloca em posição similar à das práticas globais dos gestores na reorganização do capitalismo internacional, na experiência histórica advinda da crise de 1929. Como suas práticas se aproximam notadamente daquelas de cariz fascista, nesse sentido pode-se afirmar que foi um internacionalista na fundamentação do nacionalismo brasileiro. Sua apreciação da Revolução de 1930 tinha o suporte de uma rara leitura internacionalista dos fatos que the eram contemporâneos, o que considero elemento

João Alberto da Costa Pinto: Os Gestores na organização do capitalismo... 
estrutural fundamental para caracterizá-lo como uma expressão de Intelligentsia, ou seja, como uma expressão máxima da visão de mundo dos gestores como classe dominante capitalista.

Góis Monteiro, alagoano de nascimento, teve sua carreira militar feita em grande parte no Rio Grande do Sul, mas também estudou na Escola Militar do Realengo, no Rio de Janeiro. Em Porto Alegre, com João Neves da Fontoura e Getúlio Vargas, fundou na Faculdade de Ciências Jurídicas e Sociais o Bloco Acadêmico Castilhista. Militar positivista, foi um dos mais ativos colaboradores no processo político que levou Getúlio Vargas ao poder em 1930 e foi Ministro da Guerra de Vargas (1934-1935). Afastou-se de Vargas e depois auxiliou seus opositores no golpe de 1945, tornando-se Ministro da Guerra do governo Dutra. ${ }^{10}$

Góis Monteiro manifestava suas opiniões em defesa de um inflexível nacionalismo econômico, e o fazia através de artigos e entrevistas na imprensa gaúcha e carioca. Várias dessas intervenções apareceram reunidas num livro que publicou em 1934, A Revolução de 30 e a finalidade politica do exército. Numa entrevista de 5 de novembro de 1933 ao diário O Jornal (Rio de Janeiro), intitulada "O Exército e o Brasil", coligida no livro mencionado, o militar afirmou:

Não havendo a opinião pública do país se organizado em forças nacionais, restam as forças particularistas, que não poderão mais dispor e concentrar em suas mãos os interesses da nacionalidade. Ficam só o Exército e a Marinha como instituições nacionais e únicas forças com esse caráter, e só a sombra delas é que, segundo a nossa capacidade de organização, poderão organizar-se as demais forças da nacionalidade. (MONTEIRO, 1934, p. 156)

$\mathrm{Na}$ defesa da unidade institucional do Exército, a afirmação política do gestor como organizador da nação capitalista, afinal, não poderia "existir Exército disciplinado dentro de uma nação indisciplinada" (Monteiro, 1937, p.157). E para justificar a necessidade das práticas de um nacionalismo econômico como garantia dessa nacionalidade, o general apresenta, na mesma entrevista, uma surpreendente análise global das práticas nacionalistas de outros países, que convém citar integralmente:

Para regular a vida da sociedade, vão criando novos órgãos e instituições do Estado, de modo a dar a este o poder suficiente para debelar a crise interna. O exemplo dos Estados Unidos, que procuramos imitar com a Constituição de 91, está exigindo a nossa reflexão. Isto, sem falar no que 
já fizeram a Itália, os países iberos, a Alemanha, o Japão e a Turquia, onde o genial Mustafá Kemal teve que enfrentar talvez a situação mais angustiosa. E sem citar a própria Rússia, que, humanizando-se cada vez mais, vai entrando para a fase definitiva de estabilidade e progresso nacional. Mas não é difícil de perceber que a base das transformaçōes e reforma introduzidas nesses países é o nacionalismo econômico, dirigido pelo Estado cada vez mais fortalecido. [...] A burguesia brasileira, porém, não quer compreender o estado de necessidade que se criou para o mundo inteiro e não quer abdicar de certos privilégios em benefício da nacionalidade. (MONTEIRO, 1937, p. 158-159)

O que surpreende nesta análise é o ponto de confluência do nacionalismo econômico em experiências históricas que, àquela altura (1933), eram vistas de modo tão distinto pelo senso comum. A intuição do militar não deixa de perceber, com notável acuidade, a unificação mundial de uma classe: os gestores. Afinal, seja Japão, Alemanha, Turquia, EUA, ou a Rússia comunista, o fato que lhe importava ressaltar era a organização econômica nacional, e pelo que se pode depreender de suas análises, essa organização não seria fruto da ação da burguesia, tanto assim que dirige suas críticas aos particularismos regionais capitalistas que obstavam uma eficaz ordenação capitalista nacional.

O problema não é fascista, nem nazista, nem bolchevista [...]. O problema é nitidamente brasileiro, nacional [...]. Temos que [...] regular nossa economia, evitar as lutas de classe, satisfazer as necessidades de todos pelo trabalho de todos e nos aparelhar contra qualquer submissão ao imperialismo material, moral ou mesmo espiritual de qualquer outro povo. É uma espécie de nacionalismo econômico, sem agressividade contra outras nações [...]. (MoNTeiro, 1937, p. 185-186)

Com essas constatações programáticas define-se a "Doutrina Góis Monteiro", como uma das estruturas ideológicas de maior significado na organização das práticas gestoriais do Estado brasileiro. Podem assim ser descritos, de modo sintético, os principais termos dessa "doutrina": intervencionismo,

ampla interferência estatal em todos os setores; ênfase na defesa externa e na segurança interna; preocupação com a eliminação do conflito social e político em torno da idéia nacional; industrialismo nacionalista; e a liderança das Forças Armadas, sobretudo do Exército, na condução das mudanças, a partir de uma posição hegemônica dentro do Estado. (CARVAlHo, 2005, p. 96)

João Alberto da Costa Pinto: Os Gestores na organização do capitalismo... 
A "doutrina Góis Monteiro" destaca um aspecto central na história do capitalismo, o fato de o Exército ser um dos órgãos do Estado que, por suas especificidades, vincula-se produtivamente em relação direta com o mercado capitalista (BERNARDo, 1991, p. 186). Ou seja, mesmo com todas as vicissitudes de práticas autoritárias estatistas, o Exército, na sua condição de usuário de tecnologias, é sempre a ponta de lança na articulação com os mais modernos setores produtivos privados, pela necessidade que lhe é estrutural de sempre ter de desenvolver tecnologias industriais de repressão ou tecnologias industriais de guerra. Nesse sentido, o Exército e as Forças Armadas em geral são elementos centrais na organização e realização das condições gerais de produção, por exemplo, no que se refere às tecnologias de disciplinas e à transferência das mesmas como tecnologias de controle e disciplina nas práticas de exploração da força de trabalho assalariada (BERNARDO, 1991, p. 186 -188).

A seguir e para terminar o artigo descrevo o exemplo de modelo ideológico máximo produzido pela Intelligentsia autoritária, a mais substantiva expressão ideológica de classe dos gestores: o modelo de Azevedo Amaral.

Sobre Azevedo Amaral, afirma Piva (2000): "assim como em Vianna, cultuador do Estado, há glorificação da ação empreendedora privada, que considera a força motriz da colonização, em Amaral, também estatista, da mesma maneira a realidade econômica magnificada é inteiramente privada", mas o grande problema para os dois pensadores era "o setor público artificial, fiscalista e repressor" (PIVA, 2000, p. 192). Romper com esse estado de coisas era uma das funções do Estado varguista. Ou seja, não há no modelo azevediano uma indicação estatizante da economia, mas a defesa da adoção por parte do Estado de políticas públicas antiliberais, regulatórias, que pudessem levar a organização da atividade produtiva a práticas não nocivas à nacionalidade. Amaral sempre foi um crítico radical do bovarismo intelectual das elites brasileiras. No seu diagnóstico da evolução histórica do Brasil, encontrava uma força nacional em realização no âmbito da colônia que, paradoxalmente, foi deixada de lado pelo bovarismo político das elites que conduziram a Independência e a política no Império, elites que nada percebiam do específico nacional em detrimento de práticas institucionais assemelhadas às experiências históricas da Revolução Francesa e da Revolução Americana. Contra esse bovarismo, isto é, contra essa "transplantação", como poderia dizer Werneck Sodré - grande admirador da obra azevediana - o Estado brasileiro sob a condução de Vargas recolocava os destinos do 
Brasil nos caminhos que se haviam constituído na colônia - os caminhos do autonomismo, privatista, mas consciente da realidade nacional - e abortados no Império (Amaral, 1934, p. 175 -199). Para Azevedo Amaral, o grande entrave para o Brasil de Vargas era a pesada herança da economia agrícola monocultural. Segundo Aspasia Camargo, estudiosa da obra do autor, para Amaral esse modelo produtivo era o "maior entrave à expansão das forças produtivas necessárias ao atendimento dos novos potenciais de consumo e o maior obstáculo ao equilíbrio político da sociedade pois a abandona à mercê de crises no setor exportador" (CAMARGO, 1967, p. 223). As soluções para tal quadro só poderiam advir de um outro modelo de gestão global da economia brasileira, o modelo da democracia corporativa autoritária.

\section{Para Azevedo Amaral, o Estado autoritário}

baseia-se na demarcação nítida entre aquilo que a coletividade social tem o direito de impor ao indivíduo, pela pressão da maquinaria estatal, e o que forma a esfera intangível de prerrogativas inalienáveis de cada ser humano. Assim, enquanto o Estado fascista, igualando-se nesse ponto essencial ao Estado comunista, encara os indivíduos como meras unidades a serem utilizadas na organização estatal como elementos destituidos de iniciativa e de liberdade, o Estado autoritário do tipo instituído entre nós pela Constituição de 10 de novembro [de 1937] obriga apenas o cidadão a entregar-se à coletividade no que deve e não pode deixar de pertencer a ela, mas deixa-lhe intacta a órbita em que impera soberana a sua consciência pessoal e na qual se concentram os interesses especiais que só a ele dizem respeito. (AMARAL, 1981, p. 96-97)

Desse modo,

no Estado autoritário não há compressão do indivíduo ou cerceamento das suas iniciativas e atividades, por forma a submeter a coletividade nacional à ação arbitrária do poder público em condições praticamente equivalentes a um regime de escravidão. Tanto no plano espiritual como na esfera econômica, a autoridade do Estado do tipo agora adotado no Brasil faz-se sentir sob a forma de coordenação e reajustamento das atividades dos indivíduos e dos grupos sociais, bem como pela intervenção protetora que visa preencher, pela assistência estatal, as deficiências e lacunas verificadas no tocante a assuntos que normalmente devem permanecer na órbita das responsabilidades individuais. (AMARAL, 1981, p. 97)

João Alberto da Costa Pinto: Os Gestores na organizaçāo do capitalismo... 
Segundo o modelo de Azevedo Amaral, o Estado Novo realizava, antes de tudo, as necessárias correções históricas daqueles desvios provocados por experiências equivocadas de liberalismo político e liberalismo econômico. Assim, importa mais uma vez ressalvar que o autor não era um anticapitalista, apenas um antiliberal (PIVA, 2000, p. 195), o ideólogo maior dos gestores no Brasil.

Amaral era um crítico do Estado totalitário fascista. Em seu livro de 1938 , todo o esforço conceitual foi dirigido para a caracterização diferencial desses dois regimes, atribuindo ao autoritarismo a característica de essência estruturante da moderna organização estatal das democracias modernas (Medeiros, 1978, p. 65). Esse modelo de Estado seria também o propositor de uma nova organização da economia nacional. Contrário às práticas do liberalismo econômico, Amaral defenderia um outro modelo, o da economia equilibrada. Esse modelo demarcaria o grande processo de transição que o autor percebia nas estruturas do capitalismo contemporâneo, um capitalismo científico, racionalizado. De acordo com Medeiros (1978, p. 74), Azevedo Amaral identificava o Estado moderno com o que denominava de neocapitalismo, visto como uma tradução da organização fordista, num processo de reformas progressivas visando superar os conflitos de classes.

No modelo de Azevedo Amaral, autoritarismo e economia equilibrada estão assim definidos:

O Estado corporativo e autoritário, de economia equilibrada, baseavase no princípio de que cabe ao Estado atuar no jogo das relações econômicas que se processam na vida social, corrigindo abusos, reajustando situações prejudiciais ao interesse coletivo, amparando certos grupos de interesses contra a pressão exagerada de outras forças econômicas que os poderiam prejudicar "injustamente", pois o "Estado, sendo a expressão orgânica da Nação, está investido de autoridade absoluta para coordenar, ajustar e equilibrar as correntes de qualquer natureza" ressalvando, no entanto, dentro de seu conceito de Estado autoritário, que nada haveria aí "que implique a compressão esmagadora das iniciativas e das atividades individuais". (Medeiros, 1978, p. 75)

Enfim, na síntese de Medeiros, fica caracterizada a tese azevediana de um capitalismo de iniciativa privada "não-livre", um capitalismo de democracia corporativa, tal como apresentado no modelo de Mihail Manoilesco(1938)." 
Com base no que foi apresentado, creio ter exemplificado uma concepção doutrinal de classe. As interpelações de Azevedo Amaral e de Góis Monteiro, similares a algumas outras propostas de pensadores do período, afirmam teoricamente o que já se apresentava empiricamente com o Estado Novo: as práticas de classe dos gestores na coordenação estatal do processo de criação das Condições Gerais de Produção e, como algo específico do capitalismo brasileiro, a organização, também a partir do Estado, do processo de capacitação econômica das empresas. É comum, na historiografia, caracterizar esse processo como fato de organização burocrática ou tecnocrática, entendendo-o como ação reflexa, como um espelho de demandas específicas da burguesia. Nesse ponto cabe perguntar: por que com a complexificação das práticas capitalistas privadas ao longo de quase todo o século XX, a burguesia brasileira sempre se viu "dependente", para sua própria organização privada de classe, das diretrizes do Estado nacional? Porque o Estado Nacional brasileiro, até a década de 1980, continuou sendo a única instituição capitalista nacional, viabilizada pelo longo comando de classe dos gestores nas estruturas institucionais do Estado, o que pode ser constatado pela longa permanência dos Conselhos Técnicos, que continuaram a ter um papel determinante na sugestão e organização das diretrizes políticas do capitalismo brasileiro após o golpe de 1964 (DINIZ, 1999).

The Managers in the organization of the bRazilian CAPITAlism (1930-1945)

ABSTRACT: The article presents a historiographical reflexion about the action of the Managers in the ideological organization in national bases of Brazilian capitalism in the period 1930-1945.

KEY wORDS: intellectuals, managers, Góis Monteiro, Azevedo Amaral, Brazilian capitalism.

\section{NOTAS}

1. Este é um argumento central na análise de Santos (1978).

2. A expressão é de Santos (1978, p. 102).

3. Para uma ampla descrição desse aspecto estrutural do capitalismo contemporâneo, além dos trabalhos já indicados de João Bernardo, consultar ainda Pereira (1981) e Bruno (1991).

4. No caso brasileiro, para esse período, a diferença estrutural estava no fato de que a burguesia industrial nacional ainda começava a se organizar tanto como classe política quanto como classe produtora.

João Alberto da Costa Pinto: Os Gestores na organização do capitalismo... 
5. Azevedo Amaral traduziu em 1938 o principal livro de Manoilesco (1938). No prefácio que fez à edição, Amaral endossou o modelo da "democracia corporativa" como o modelo político mais adequado à realidade brasileira, contudo, nesse mesmo prefácio, fez questão de enfatizar a sua discordância em relação a Manoilesco pela associação que este fez do corporativismo ao modelo fascista, sobretudo o fascismo italiano de Mussolini. Para Amaral a democracia corporativa nunca poderia ser expressão do fascismo porque este tinha uma natureza histórica intrinsecamente autoritária [sic] enquanto que a democracia corporativa realizava efetivamente uma democracia social por se antepor às práticas privatistas e egoístas da democracia liberal (MANOILESCO, 1938, p. VVII).

6. Os trabalhos de Mendonça (2000) e de Diniz \& Boschi (1978) oferecem um amplo quadro descritivo-analítico de estudos com essa notação "ortodoxa" e reificada das relações de classe nas práticas institucionais do aparelho de Estado, estudos que na sua integralidade - mesmo que com substantivas diferenças referem-se a um Estado "autonomizado" politicamente das relações elementares da organização da exploração da classe operária; quase sempre um Estado "palco" de múltiplos "atores", as tais "frações" da burguesia e suas "classes auxiliares", as burocracias.

7. Na minha tese de doutorado (PINTO, 2005), realizei uma investigação sobre as trajetórias de Caio Prado Júnior, Gilberto Freyre e Nelson Werneck Sodré, em que pude demonstrar que os três intelectuais, naquele período em questão, apesar de serem nomes de expressão nacional, não se firmavam ainda como Intelligentsia, como produtores de visões de mundo de classe. Os três autores só atingiram essa marca emblemática nas décadas de 1950 e 1960 e, sob o meu ponto de vista, afirmaram com suas obras visões de mundo de frações da classe dos gestores, remontando assim a especificidades estruturais dos projetos tanto de Azevedo Amaral (Caio Prado Júnior e Nelson Werneck Sodré) como de Góis Monteiro (Gilberto Freyre). Não porque reendossassem as teses da democracia corporativa (Caio Prado Júnior na minha interpretação sempre se manteve próximo a essa tese), mas porque referendavam as práticas ampliadas dos gestores nas estruturas do Estado e em outras bases institucionais, como os sindicatos (caso de Nelson Werneck Sodré). Pelo caráter ampliado de classe nas suas práticas institucionais desse período era visível o estabelecimento de dois "campos políticos" de classe, aquele que preservava um viés autoritário, de manutenção coordenadora do Estado sob a lógica da reprodução do capital (Gilberto Freyre) e aquele que percebia as possibilidades institucionais de autoorganização dos trabalhadores (Nelson Werneck Sodré), isto é, um campo político de radicalização da democracia, curiosamente o que se refere a uma velada aproximação com o modelo autoritário (na matriz azevediana). Nesse contexto o autor que "menos" (não vai aqui nenhum juízo de valor; trata-se da constatação de um fato!) se envolveu com a política dos fatos imediatos foi justamente Caio 
Prado Júnior. Note-se que essa é uma hipótese que demarca uma divisão num mesmo campo de classe, rupturas políticas no quadro global da classe dos gestores. O Golpe de 1964 reequacionou essas práticas e os gestores retomaram a sua perspectiva autoritário-instrumental.

8. Em Goldmann (1984) apresenta-se a seguinte definição de "estruturas significativas": "Uma das teses fundamentais tanto da psicanálise no plano individual como do pensamento dialético no plano social e histórico reside precisamente em admitir que todos os fatos humanos possuem, enquanto tais, um caráter de estruturas funcionais, quer dizer, de estruturas significativas. $\mathrm{O}$ seu estudo pressupõe, pois, por um lado, uma análise interna, compreensiva, cuja função consiste em pôr em evidência a estruturação imanente $e$, a partir daí, o significado eventual dos diversos elementos envolvidos em tal ou tal relação, e, por outro lado, uma análise externa, explicativa, incidindo sobre a inserção da estrutura enquanto elemento funcional numa estrutura englobante" (p. 86). Ainda sobre esse conceito, conferir a análise do pensador goldmanniano Löwy (2002) onde se lê: "A estrutura social condiciona a estrutura significativa da obra; mas, para apreender a evolução da obra, seu nascimento, seu desenvolvimento, suas mudanças e reorientações, há de se considerar os acontecimentos históricos da sociedade global, do grupo ao qual o pensador pertence, ou da classe com a qual se identifica. A conjuntura histórica social, e não somente a estrutura abstrata, é o quadro do pensamento: para compreender a trajetória política de Marx, não basta relacioná-la com o 'proletariado, enquanto posição no processo de produção, mas também é preciso aproximá-la do desenvolvimento concreto do movimento operário - greves, sublevaçŏes, evolução dos sindicatos, dos partidos etc." (p. 29, nota 7).

9. O termo "máximo de consciência possível" origina-se da obra clássica de Lukács (2003), onde se lê: "A relaçăo com a totalidade concreta e as determinações dialéticas dela resultantes superam a simples descrição e chega-se à categoria da possibilidade objetiva. Ao se relacionar a consciência com a totalidade da sociedade, torna-se possível reconhecer os pensamentos e os sentidos que os homens teriam tido numa determinada situação da sua vida, se tivessem sido capazes de compreender perfeitamente essa situação e os interesses dela decorrentes, tanto em relação à ação imediata, quanto em relação à estrutura de toda a sociedade conforme esses interesses" (p. 141). Sobre esse conceito, Löwy (2002), faz a seguinte observação: "essa 'consciência de classe possível' não poderia ser confundida com a consciência psicológica da classe, ou seja, os 'pensamentos empíricos efetivos', 'os pensamentos psicologicamente descritiveis e explicáveis que os homens de sua situação vital', conjunto heteróclito de concepções mais ou menos confusas (freqüentemente misturadas com elementos ideológicos de outras classes), de aspirações e desejos vagos, de projetos de transformaçăo social" (p. 36).

João Alberto da Costa Pinto: Os Gestores na organizaçăo do capitalismo... 
10. Estes dados estão na apresentação da resenha do livro de Góis Monteiro, incluída na obra de Oliveira, Lúcia Lippi et al., 1980, p. 245-248.

11. Os termos "economia equilibrada" e "iniciativa privada não-livre" aparecem de modo similar (creio ser muito mais do que uma coincidência semântica porque se trata de concordância conceitual), ao longo da obra de Caio Prado Júnior. Sobre essa hipótese, a de um Caio Prado Júnior azevediano, consultar Pinto, 2005.

\section{REFERÊNCIAS}

Amaral, Azevedo. O Brasil na crise actual. Säo Paulo: Cia. Editora Nacional, 1934. O estado autoritário e a realidade nacional. Brasília: Editora da UnB, 1981.

Berle. Adolfo Augustus; MeAns, Gardiner. A moderna sociedade anônima e a propriedade privada. São Paulo: Nova Cultural, 1988.

Bernardo, João. Marx crítico de Marx. Epistemologia, classes sociais e tecnologia em O capital, t. III. Porto: Afrontamento, 1977. . O inimigo oculto. Porto: Afrontamento, 1979. . Capital, sindicatos, gestores. São Paulo: Vértice, 1987. . Economia dos conflitos sociais. São Paulo: Cortez, 1991. . Labirintos do fascismo. Na encruzilhada da ordem e da revolta. Porto: Afrontamento, 2003.

BRUNo, Lúcia. Gestores: a prática de uma classe no vácuo de uma teoria. In: BRUNo, Lúcia; Saccardo, Cleusa (Coord.). Organização, trabalho e tecnologia. São Paulo: Atlas, p. 115-141, 1986.

Reestruturação capitalista e estado nacional. In: Oliveira, Dalila Andrade; Duarte, Marisa R. T. Política e trabalho na escola. Administração dos sistemas públicos de educaçăo básica. Belo Horizonte: Autêntica, p. 13-41, 1999.

Camargo, Aspásia. A teoria política de Azevedo Amaral. Revista Dados, 2 e 3, Rio de Janeiro, Iuperj, p. 194-224, 1967.

Campos, Francisco. O estado nacional. Sua estrutura. Seu conteúdo ideológico. Rio de Janeiro: José Olympio, 1940.

Carvalho, José Murilo de. Forças armadas e política no Brasil. Rio de Janeiro: Jorge Zahar, 2005.

Coelho, Edmundo Campos. Em busca de identidade: o exército e a política na sociedade brasileira. Rio de Janeiro: Record, 2000.

Coutınho, Lourival. O General Góes depöe... Rio de Janeiro: Livraria Coelho Branco, 1956. 
Dinız, Eli. Engenharia institucional e políticas públicas: dos conselhos técnicos às câmaras setoriais. In: PANDOLFI, Dulce (Org.). Repensando o Estado Novo. Rio de Janeiro: FGV, p. 21-38, 1999.

DinIZ, Eli; Boschi, Renato Raul. Empresariado nacional e estado no Brasil. Rio de Janeiro: Forense-Universitária, 1978.

Galbratth, John Kenneth. Contando vantagens. Minhas memórias com Roosevelt, Trumam, Kennedy e outros. Rio de Janeiro: Record, s.d.

Goldmann, Lucien. Dialética e cultura. Rio de Janeiro: Paz e Terra, 1979.

Epistemologia e filosofia política. Lisboa: Editorial Presença, 1984.

Lowy, Michael. Goldmann e o estruturalismo genético. Serviço Social e Sociedade.

São Paulo: Cortez, n. 21, ago. p. 66-80, 1986.

. A teoria da revolução no jovem Marx. Petrópolis: Vozes, 2002.

LuKÁCS, George. História e consciência de classe. São Paulo: Martins Fontes, 2003.

Manoilesco, Mihail. O século corporativo. Doutrina do corporativismo integral e puro. Tradução de Azevedo Amaral. Rio de Janeiro: José Olympio, 1938.

MAZA, Fábio. O idealismo prático de Roberto Simonsen. Ciência, tecnologia e indústria na construção da nação. São Paulo: Fiesp/Ciesp/IRS, 2004.

MedeIros, Jarbas. Ideologia autoritária no Brasil 1930-1945. Rio de Janeiro: FGV, 1978.

Mendonça, Sônia Regina de. Estado e economia no Brasil: opções de desenvolvimento. Rio de Janeiro: Graal, 2000.

Monteiro, Góis. A Revolução de 30 e a finalidade política do exército. Rio de Janeiro: Assis Cintra e Andersen Editores, s.d. [1934], p. XXX.

Oliveira, Lúcia Lippi et al. (Coord.). Elite intelectuale debate político nos anos 30 . Rio de Janeiro: FGV/INL/MEC, 1980.

Pereira, Luiz Carlos Bresser. A sociedade estatal e a tecnoburocracia. São Paulo: Brasiliense, 1981.

PINTo, João Alberto da Costa. Os impasses da intelligentsia diante da Revolução Capitalista no Brasil (1930-1964): historiografia e política em Gilberto Freyre, Caio Prado Júnior e Nelson Werneck Sodré. 2005. Tese (Doutorado) - Programa de Pós-Graduação em História da Universidade Federal Fluminense, UFF, Niterói, 2005.

PINTo, Sérgio Murilo. A doutrina Góis: síntese do pensamento militar no Estado Novo. In: PANDolf1, Dulce (Org.). Repensando o Estado Novo. Rio de Janeiro: FGV, p. 291-307, 1999.

PIVA, Luís Guilherme. Ladrilhadores e semeadores: a modernização brasileira no pensamento político de Oliveira Vianna, Sérgio Buarque de Holanda, Azevedo Amaral e Nestor Duarte (1920-1940). São Paulo: Editora 34, 2000.

João Alberto da Costa Pinto: Os Gestores na organização do capitalismo... 
SANTOS, Wanderley Guilherme dos. Ordem burguesa e liberalismo político. São Paulo: Duas Cidades, 1978.

Simonsen, Roberto. A planificaçăo da economia brasileira (parecer apresentado ao Conselho Nacional de Política Industrial e Comercial). São Paulo: Fiesp, 1944.

SODRÉ, Nelson Werneck. História do militar do Brasil. Rio de Janeiro: Civilização Brasileira, 1979.

SouzA, Célia Aparecida de. O IDORT e suas ações políticas entre 1931-1937. In: Mendonç, Sônia Regina de (Org.). O Estado Brasileiro: agências e agentes. Niterói: Eduff/Vício de Leitura, 2005, p. 219-231.

VARGAS, Getúlio. A nova política do Brasil (v. 10, O Brasil na guerra). Rio de Janeiro: José Olympio, 1944.

VIANna, Oliveira. Problemas de política objetiva. Rio de Janeiro: Record, 1974. 